\title{
Timpanik Membran Görüntü Özellikleri Kullanılarak Sınıflandırılması
}

\author{
Erdal BAŞARAN ${ }^{1 *}$, Zafer CÖMERT ${ }^{2}$, Yüksel ÇELIK ${ }^{3}$
}

${ }^{1}$ Bilgisayar Teknolojileri, Meslek Yüksek Okulu, Ağrı İbrahim Çeçen Üniversitesi, Ağrı, Türkiye

${ }^{2}$ Yazılım Mühendisliği, Mühendislik Fakültesi, Samsun Üniversitesi, Samsun, Türkiye

${ }^{3}$ Bilgisayar Mühendisliği, Mühendislik Fakültesi, Karabük Üniversitesi, Karabük, Türkiye

${ }^{* 1}$ ebasaran@ agri.edu.tr, ${ }^{2}$ zcomert@ samsun.edu.tr, ${ }^{3}$ yukselcelik@ karabuk.edu.tr

Öz: Orta kulak inflamasyonu olarak bilinen otitis media rahatsızlı̆̆ının teşhis edilmesi için otoskop cihazı ile zar bölgesine bakılarak karar verilmektedir. Dokusal özellik çıkarma algoritmaları, görüntüler üzerinde bölge tespiti ve görüntüye ait özelliklerin elde edilmesinde yaygın olarak kullanılmaktadır. Bu çalışmada gerekli yasal izinler alındıktan sonra elde edilen orta kulak görüntülerinde normal ve otitis media görüntülerinin ayırt edilmesi için literatürde yaygın olarak kullanılan gri seviyeli eş-oluşum matrisi, yerel ikili örüntüler, yönlü gradyanların histogram algoritmaları kullanılmıştır. Bu dokusal özellik çıkarma algoritmalarının görüntüleri sınıflandırma üzerinde başarıları incelendikten sonra her bir özellik setine görüntülere ait renk kanallarının ortalamaları da eklenerek bu özelliğin sınıflandırma başarısına etkisi incelenmiştir. Sonuç olarak tek başına bir dokusal özellik çıkarma algoritması kullanıldığında en iyi sonuçlar yerel ikili örüntü algoritması ile elde edilmiştir. Bu algoritmaya renk kanallarının ortalaması da eklendiği zaman sınıflandırma başarısını olumlu yönde etkilediği sonucuna varılmıştır. Sınıflandırma sonucunda \% 78.67 doğruluk oranı elde edilmiştir.

Anahtar kelimeler: Biyomedikal işaret işleme, yapay öğrenme, özellik çıkarımı, sınıflandırma.

\section{Classification of Tympanic Membrane Using Image Features}

\begin{abstract}
In order to diagnose otitis media, known as middle ear inflammation, is made by looking at the membrane area with an otoscope device. Textural feature extraction algorithms are widely used to detect regions on images and to obtain image properties. In this study, gray-level co-occurance matrix, local binary patterns, histogram of oriented gradients, which are widely used in the literature, were used to distinguish normal and otitis media images in middle ear images obtained after obtaining the necessary legal permissions. After examining the success of these textural feature extraction algorithms on image classification, the averages of the color channels of the images were added to each feature set, and the effect of this feature on the classification success was examined. As a result, when using a textural feature extraction algorithm alone, the best results were obtained with the local binary pattern algorithm. When the average of color channels is added to this algorithm, it is concluded that it affects the classification success positively. As a result of the classification, an accuracy rate of $78.67 \%$ was obtained.
\end{abstract}

Key words: Biomedical signal processing, artificial learning, feature extraction, classification.

\section{Giriş}

İşitme duyu organımız olan kulak, ses dalgalarını dış ve orta kulak boyunca iç kulağa doğru ilerler ve burada ses dalgalarını daha da güçlendirir ve beyne gönderilmek üzere elektrik sinyallerine dönüştürülür [1]. Orta kulak, timpanik membran (TM), kemikçikler, kemikçikler arasındaki eklemler, kaslar, bağlar ve orta kulak boşluğundan oluşur [2]. Kulak yapısı Şekil 1'de verilmiş̧ir.

\footnotetext{
* Sorumlu yazar: ebasaran@agri.edu.tr. Yazarların ORCID Numaraları: ${ }^{1}$ 0000-0001-8569-2998, ${ }^{2}$ 0000-0001-5256-7648, ${ }^{3}$ 0000-0002$7117-9736$
} 


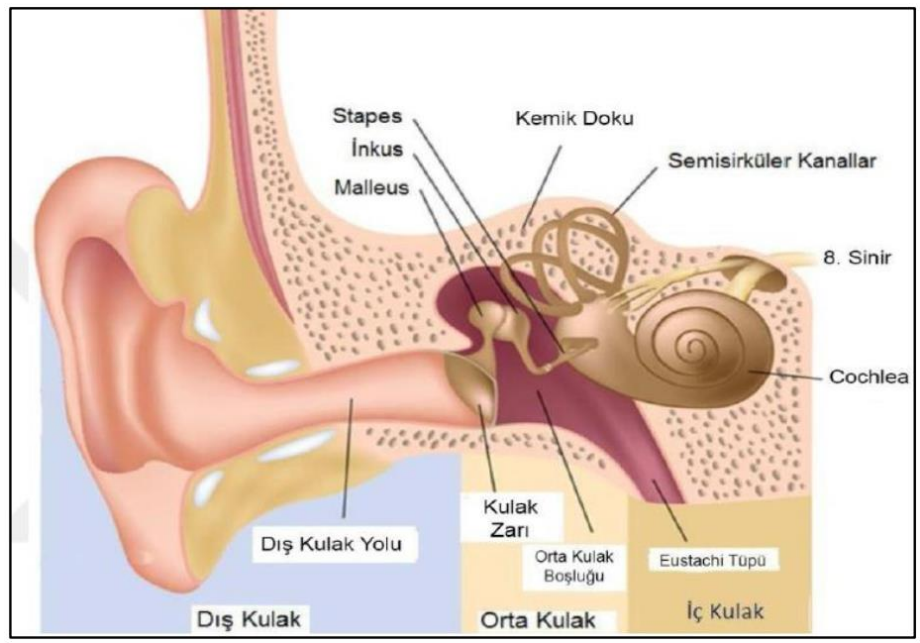

Şekil 1. Kulak Yapısı [1]

Otitis media (OM), orta kulağın iltihaplı ve enfektif olma durumu olarak bilinmektedir [4]. Orta kulakta sıv1 birikmesi, iltihaplanma ve ağrı ile kendini gösterir [5]. Bu hastalık çocuklarda en yaygın görülen hastalıkların biridir. Bunun yanı sıra ameliyata ve antibiyotiklerin reçetelenmesinin en yaygın nedenidir [6]. OM, klinik olarak incelendiğinde yaygın olarak akut otitis media, kronik otitis media, efüzyonlu otitis media çeşitlerinden oluşmaktadır [7]. Akut OM; kulak ağrısı, kulak zarında bombeleşme, sıvı birikmesi, kulak zarında kızarıklık ve genellikle üst solunum yolu enfeksiyonu ile kendini göstermektedir [8][9]. Kronik OM ise akut OM ve efüzyonlu OM'nin tıbbi tedaviye rağmen 6 hafta ile 3 ay arasında devam etmesi veya Dünya Sağlık Örgütüne göre 2 hafta efüzyonun devam etmesi olarak kabul edilmektedir [10].

OM, tanısının konmasına yönelik olarak biyomedikal orta kulak görüntüleri ile literatürde yapılan çalışmalara bakıldığı zaman; ilk olarak zar bölgesinin tespit edilmesine yönelik olarak Active Contour Segmentation yöntemi kullanılmıştır. Ardından zar bölgesi tespit edildikten sonra gird renk momentleri (grid color moment), yerel ikili örüntü (local binary pattern) ve yönlü histogramların gradyanları dokusal özellik çıkarma (texture featre extraction) algoritmaları ile özellik seti elde edildikten sonra Gabor özellikleri de eklenerek AdaBoost yöntemi ile görüntüler sınıflandırılmıştır [11]. Video otoskop cihazı ile elde edilen görüntülerin görsel olarak daha iyi analiz edilebilmesi için Lineer Unsharp algoritması ve alçak geçiren filtreleme kullanılarak orta kulakta bulunan kemikçiklerin ve lezyon bölgesinin daha belirgin görülmesi sağlanmıştır [12]. Diğer yandan Akut OM, Efüzyonlu OM ve efüzyonlu olmayan OM 135 adet görüntünün sınıflandırılması için zar bölgesi Active Contour Segmentasyon yöntemi ile tespit edilmiştir. Zar bölgesinde bulunan kabarcıklar için kenar çıkarma algoritmaları kullanılmıştır ve gri bölge tespiti için K-Means kümele kullanılarak özellik seti elde edildikten sonra hiyerarşik ağaç şeması kullanılarak \%84 doğruluk oranı ile sınıflandırma yapılmıştır. Dokusal özellik çıkarma algoritması ve ortak kulak görüntülerinin renk kanallarının ortalama değerleri çıkarılarak elde edilen özellik seti ile yapılan bir diğer çalışma yapay sinir ağları yöntemi ile sınıflandırılarak \%76 doğruluk oranı elde edilmiştir [13]. OM görüntüleri ile manuel olarak özellik çıkarılarak yapılan sınıflandırma çalışmalarının yanında özellik setinin otomatik elde edildiği derin öğrenme yöntemleri ile zar bölgesinin tespit edildiği, CNN modellerinin özellik katmanları elde edildikten sonra özellik seçim algoritmalarının kullanıldığı ve sınıflandırma işlemlerinin yapıldığı çalışmaların olduğu belirlenmiştir [14]-[19].

Son yıllarda birçok hastalık için yapay zekâ kapsamında değerlendirilen makine öğrenme yöntemleri ve derin öğrenme yöntemleri kullanılarak karar destek sistemleri geliştirilerek hastalığın teşhis edilmesinde önemli rol oynadı ğ gözlemlenmiştir [20]-[26].

$\mathrm{Bu}$ çalışmada literatürde yaygın olarak kullanılan biyomedikal görüntülerde dokusal özellik çıkarma algoritmalarından gri seviyeli eş-oluşum matrisi, yerel ikili örüntü ve yönlü gradyanların histogramı kullanılarak elde edilen özellik setinin Normal TM ve Anormal TM görüntülerini sınıflandırma başarısı üzerindeki etkileri incelenmiştir. Ardından orta kulak görüntülerinin ortalama renk değerleri de alınarak özellik setine eklendikten sonra makine öğrenme yöntemlerinden $\mathrm{k}$ en yakın komşuluk algoritması $(\mathrm{kNN})$ ve destek vektör makinaları (DVM) yöntemleri ile sınıflandırılarak görüntüleri ayırt etme başarısına olan etkisi incelenmiştir.

Bu çalışmanın kalan kısmı şu şekilde organize edilmiştir: ikinci bölünme deneysel çalışmada kullanılan materyal ve yöntemler açıklanmıştır. Çalışmanın üçüncü kısmında deneysel sonuçlar ve literatürde yapılmış 
benzer çalışmalar ile karşılaştırmaya değinilmiştir. Dördüncü bölümünde sonuç ifadeleri olacak şekilde sunulmuştur.

\section{Materyal ve Metotlar}

Bu çalışmada Normal TM ve anormal TM görüntülerinin sınıflandırılması için ilk olarak görüntüler yeniden boyutlandırılmıştır. Dokusal özellik çıkarma algoritmaları olan Gri Seviyeli eş-Oluşum Matrisi (GSEM) ve Yerel İkili Örüntü (YİÖ) algoritmaları ile özellik çıkarmak için görüntüler gri renge dönüştürülmüştür. Yönlü Gradyanların Histogramı (YGH) algoritması ile özelik elde edilmesi için renkli görüntüler kullanılmıştır. Her bir Dokusal özellik çıkarma algoritmasının TM görüntülerini ayırt etme üzerindeki performans sonuçları izlenmiştir. $\mathrm{Bu}$ çalışmada algoritmalardan elde edilen özelliklere TM görüntülerine ait renk kanallarının ortalama değerleri (RKO) alınarak sınıflandırma başarı üzerine etkisi incelenmiştir. Yapılan çalışmanın akış diyagramı Şekil 2'de verilmiştir.

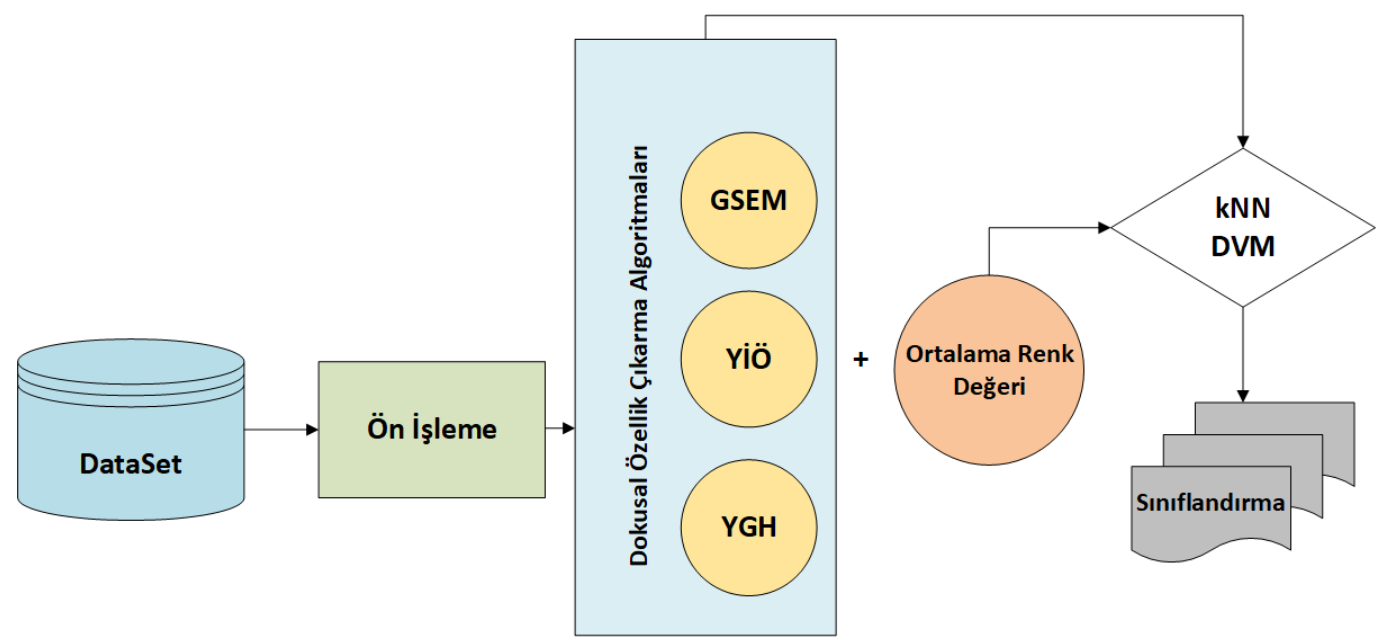

Şekil 2. Deneysel çalışmanın akış diyagramı

\subsection{Veri seti}

Bu deneysel çalışma kapsamında kullanılan veri seti, yasal izinler alındıktan sonra 10/2018-06/2020 tarihleri arasında otoskop cihazı ile orta kulak görüntüleri toplanmıştır. Görüntüler elde edildikten sonra kulak burun boğaz (KBB) uzmanı tarafından her bir görüntü etiketlenerek klasörlere yerleştirilmiştir. Toplamda elde edilen 956 adet orta kulak görüntülerinin 535 adedi normal sınıfa sahip iken 421 tanesi anormal sınıfa sahiptir. Oluşturulan veri seti açık erişimli olarak araştırmacılara sunularak literatüre kazandırılmıștır. Bu çalışmada kullanılan veri setine araştırma grubumuzun web sayfasından (http://www.ctganalysis.com/Category/otitis-media) erişilebilmektedir.

\subsection{Gri Seviyeli Eş-Oluşum Matrisi (GSEM)}

GSEM, farklı gri seviyeli pikseller arasındaki uzamsal ilişkiyi temsil edebilen bir istatistiksel yöntemdir [27]. Bir görüntüde farklı bölgelerdeki birbirleri ile ilişkili olan yoğunluk değerlerinin istatiksel bilgileri kullanılarak ikinci dereceden dokusal özellikleri çıkarmak için kullanılan bir algoritmadır [28]. GSEM, görüntülerin yerel modellerini analiz etmenin temeli olan yön, bitişik aralık ve varyasyon aralığı hakkındaki görüntünün gri düzeyine ait kapsamlı bilgilerini yansıtabilir [29]. Şekil 3'de görüntüdeki piksel çiftlerinin eş oluşum matrisinde gösterilmektedir. 


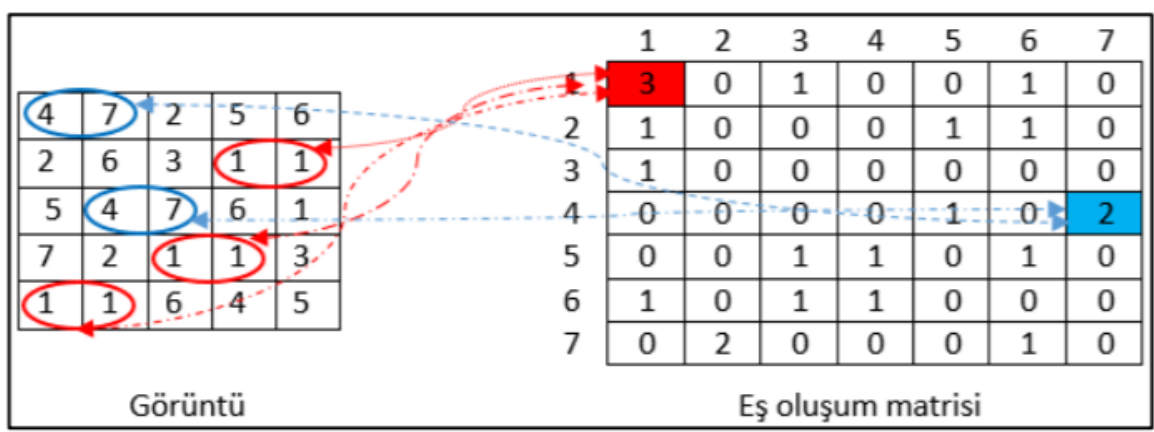

Şekil 3. Görüntü pikselleri ve eş oluşum matrisi

GSEM, gri renkli görüntülerde pikseller arasındaki açı $(\theta)$ ve uzaklığa ( $\delta$ ) göre GSEM Denklem (1)'deki gibi hesaplanmaktadır.

$M \delta, \theta=0(p, q) \sum_{n=1}^{N} \sum_{m=1}^{K}\left\{\begin{array}{lr}1 & I(n, m)=p \\ & I(n, m+\delta)=q\end{array}\right.$

Denklem (1)'de p ve q değerleri görüntüdeki gri rengin yoğunluğunu; $N$, K ise görüntünün boyutunu ifade etmektedir. Eşitlikte belirttiği üzere belirlenen bir $\theta$ açı yönünde ve $\delta$ uzaklık değerlerine bağlı olarak değişmektedir. Burada $\theta$ açısı genellikle $0^{0}, 45^{\circ}, 90^{\circ}$ ve $135^{\circ}$ olarak alınmaktadır. GSEM'ye dayanılarak istatiksel olarak birçok özellik hesaplanabilir. Bu çalışma kapsamında homojenlik, kontrast, korelasyon ve enerji değerleri Denklem 2.1-2.4'e göre hesaplanarak her bir TM görüntüsünün özelliği elde edilerek özellik vektörü oluşturulmuştur.

$$
\begin{aligned}
& \text { Homojenlik }=\sum_{i, j}\left(\frac{P(i, j)}{1+|i-j|}\right) \\
& \text { Korelasyon }=\sum_{i, j}\left(\frac{\left(i-\mu_{\mathrm{x}}\right)\left(j-\mu_{\mathrm{x}}\right) P(i, j)}{\sigma_{\mathrm{x}} \sigma_{\mathrm{y}}}\right) \\
& \text { Kontrast }=\sum_{i, j}|i-j|^{2} P(i, j) \\
& \text { Enerji }=\sum_{i, j} P(i, j)^{2}
\end{aligned}
$$

Denklem 2.1-2.4'te $i, j$ değerleri pikselin konumlarını ifade etmektedir. $P(i, j)$ değeri ise bileşik durum olasılık yoğunluk fonksiyonunu, $\mu_{\mathrm{x}}$ ve $\mu_{\mathrm{x}}$ piksellerin ortalama değerini ifade ederken $\sigma_{\mathrm{x}}, \sigma_{\mathrm{y}}$ ise standart sapma değerlerini ifade etmektedir.

\subsection{Yerel İkili Örüntü}

Yerel ikili örüntü (YİÖ), temel olarak merkezdeki bir pikselin komşu piksel ile karşılaştırmaktır [3]. YİÖ merkez piksel ile komşu piksel arasındaki yoğunluk ilişkisine bakmaktadır [4].Gri renkli görüntülere uygulanan bu algoritma merkezde bulunan piksel değeri komşu piksel ile karşılaştırılır eğer komşudan büyükse 1 olarak kodlanır değilse 0 olarak kodlanır [5].

$\left(x_{c} y_{c}\right)$ bir piksel verildiğinde, YİÖ aşağıdaki Denklem 3'deki gibi matematiksel olarak hesaplanıp ondalık biçimde elde edilebilmektedir:

$Y \dot{\mathrm{IOO}}\left(x_{c} y_{c}\right)=\sum_{p=0}^{p-1} s\left(i_{p}-i_{c}\right) \cdot 2^{p}$

Denklem (3)'de p merkezin etrafında bulunan piksellerdir. $i_{p}$ ve $i_{c}$ sırasıyla yarıçapı $\mathrm{R}$ olan dairenin komşuluğundaki merkezi pikselin gri düzey değerlerini 0-255 aralığında belirlemektedir. Sc(x) Denklem (4)'teki gibi belirlenir:

$\mathrm{S}_{\mathrm{c}}(\mathrm{x})=\left\{\begin{array}{l}0, \text { ĕger } x<0 \\ 1, \text { ĕger } x \geq 1\end{array}\right.$ 
Burada $x$ merkez piksel ile komşu piksel arasındaki farkı ifade etmektedir. Bu çalışmada komşu piksel değeri 8 olarak belirlenirken, yarıçap boyutu ise 1 olarak belirlenmiştir ve her bir TM görüntüsüne ait özellik vektörü elde edilmiştir.

\subsection{Yönlü Gradyanların Histogramı}

Dalal ve Triggs [6] tarafından önerilen gradyan tabanlı bir dokusal özellik çıkarma algoritmasıdır. Yönlü Gradyanların Histogramı (YGH)'nin temeli, yerel gradyanların dağılımını kullanarak bir nesnenin görünümü ve şekli ile ilgili özellikleri çıkarmaktır [7]. Güçlü bir doku ve şekil tanımlama yeteneğine sahiptir. Görüntüdeki ışık değişikliklerine karşı sağlamlığı ve yerel geometrik dönüşümlere karşı değişmezliği nedeniyle YGH, insan tespiti, karakter tanıma ve yüz tanımada başarıyla kullanılmıştır [8]. Gradyan oryantasyonları N kutu olarak nicelendirilir. Ardından görüntü M sayıda eşit alt bölgeye bölünür. Her bir alt bölge için, bir yönelim histogramı hesaplanır [9].

\section{5. k En Yakın Komşuluk}

$k \mathrm{NN}$ yöntemi test kümesinde bulunan bir verinin sınıfının belirlenmesi için eğitim kümesinde bulunan her bir örneğe uzaklık fonksiyonu ile karşılaştırılarak bulunmaktadır. En yakın komşular genellikle bitişiğindeki bilinmeyen noktaya en kısa mesafeli noktalar olarak belirlenir [10]. Bu algoritmanın iki temel bileşeni vardır. Biri uygun $\mathrm{k}$ değerini seçmek diğeri ise uygun fonksiyonu seçmektedir [11]. Bu deneysel çalı̧̧mada uzaklık fonksiyonu olarak Öklid kullanılmıştır. 1,2,5 ve 10 komşuluk değerlerine bakılarak test kümesindeki verilerin sınıfı belirlenmiştir.

\subsection{Destek Vektör Makinaları (DVM)}

Denetimli bir öğrenme modeli olan DVM, sınıflandırma ve regresyon problemlerinde yaygın olarak kullanılmaktadır. Destek vektör makinesi (DVM), hiper düzlemlerde iki sınıfın ayırma sınırı arasındaki marjı maksimum düzeye çıarmak için verimli bir sınıflandırma yöntemidir [12]. Doğrusal olarak ayırılabilen bir DVM, iki doğru marjı oluşturulur ve bu doğrulara veriler paralel olarak dağıtılmaktadır [13]. Her bir veriye ait sınıf Denklem (5)'deki gibi hesaplanmaktadır.

$y(x)=W_{x_{t}}+b$

Denklem (5)'de W her bir değişkenin ağırlığına karşılık gelmektedir. b bias değeri iken $x_{t}$ ise verinin sınıfını belirtmektedir.

Doğrusal olarak ayırılamayan problemlerde çekirdek fonksiyonu kullanılmaktadır. Çekirdek fonksiyonunun kullanılması ile giriş verilerini daha yüksek boyutlu bir alana eşleyebilir; böylece ek alan, ayırıcı bir hiper düzlem bulmak için daha büyük bir firsat sağlanmış olur [41]. DVM'de yaygın olarak doğrusal, radyal temelli fonksiyon, polinom ve gauss çekirdek fonksiyonları kullanılmaktadır [41][42]. Hangi çekirdek fonksiyonunun kullanılması ile ilgili net bir koşul bulunmamaktadır fakat yapılan çalışmaların çoğunda radyal temelli fonksiyon ile daha başarılı sonuçlar elde edildiği belirlenmiştir [41],[42]. Bu çalışmada da çekirdek fonksiyonu olarak radyal temelli fonksiyon kullanılmıştır. Radyel temelli fonksiyon matematiksel olarak Denklem (6)'da verilmiştir.

$$
K\left(x_{i,}, x_{j}\right)=e^{-\gamma\left(x_{i},-x_{j}\right)^{2}}
$$

Denklem 6'da $x_{i}$ ve $x_{j}$ piksel noktalarını ifade ederken, $\gamma$ (gamma) ise kernelin dağılım derecesini belirleyen parametredir.

\section{Bulgular}

$\mathrm{Bu}$ çalışmada dokusal özellik çıkarma algoritmaları ve renk kanallarının ortalaması özelliklerinin sınıflandırma başarısı üzerine etkisini ölçmek için hata matrisinden yararlanılmıştır. Hata matrisinde gerçek değerler ve tahmin edilen değerler bulunmaktadır. Doğru pozitif (DP) ve doğru negatif (DN) veri setinde doğru olarak tanımlanmış örnekleri ifade ederken, yanlış pozitif (YP) ve yanlış negatif (YN) ise yanlış tanımlanan örnekleri ifade etmektedir. Model performansını değerlendirmek için hata matrisinden doğruluk, hassaslık, özgüllük değerleri hata matrisinden elde dilmiştir [20]. Tablo 1'de matematiksel olarak ifade edilmiştir. 
Tablo 1 Hata matrisinden elde edilen performans ölçütleri

\begin{tabular}{ccl}
\hline Doğruluk & \multicolumn{1}{c}{\begin{tabular}{cl} 
Modelin tüm veri seti üzerindeki \\
\cline { 2 - 3 } Duşarısını belirtir
\end{tabular}} \\
\hline Duyarlık & $\frac{D P}{D P+Y N}$ & $\begin{array}{l}\text { Anormal TM görüntülerini ayırt } \\
\text { etme başarısını ifade eder }\end{array}$ \\
\hline Özgüllük & $\frac{D N}{D N+Y P}$ & $\begin{array}{l}\text { Normal TM görüntülerini ayırt etme } \\
\text { başarısını ifade eder }\end{array}$ \\
\hline
\end{tabular}

Normal TM ve Anormal TM görüntülerini ayırt etmek için ilk deneysel çalışmada GSEM özellikleri elde etmek için enerji, kontrast, homojenlik ve entropi özelliğinden yararlanılmıştır. Açısal değer olarak $0^{\circ}, 45^{\circ}, 90^{\circ}$ ve $135^{\circ}$ ve uzaklık değeri olarak 1 alınmıştır. Ardından bu özellik setine RKO da eklenerek bu algoritma ile kullanılmasının sınıflandırma başarısına etkisi incelenmiştir. Model eğitmek için veri setinin \%70’i eğitim ve \%30 test olacak şekilde ayırılmıştır. Ayrıca 5-katlı çapraz doğrulama sonuçlarına da bakılmıştır.

Tablo 2. GSEM algoritması ile Normal TM ve Anormal TM görüntülerinin sinıflandırma sonuçları (\%70 - \%30).

\begin{tabular}{lllll}
\hline Yöntem & \multirow{2}{*}{ Ozellik } & $\begin{array}{l}\text { Doğruluk } \\
\text { oranı }(\boldsymbol{\%})\end{array}$ & $\begin{array}{l}\text { Hassaslık } \\
(\boldsymbol{\%})\end{array}$ & $\begin{array}{l}\text { Özgüllük } \\
(\boldsymbol{\%})\end{array}$ \\
\hline $\mathrm{kNN}(\mathrm{k}=1)$ & GSEM & 67.13 & 67.03 & 66.20 \\
\hline $\mathrm{kNN}(\mathrm{k}=2)$ & GSEM & 59.79 & 62.91 & 60.83 \\
\hline $\mathrm{kNN}(\mathrm{k}=5)$ & GSEM & 65.38 & 65.10 & 64.48 \\
\hline kNN (k=10) & GSEM & 63.63 & 63.63 & 62.59 \\
\hline DVM & GSEM & 66.78 & 66.70 & 66.62 \\
\hline
\end{tabular}

Tablo 3. GSEM algoritması ile Normal TM ve Anormal TM görüntülerinin sınıflandırma sonuçları (5-katlı çapraz doğrulama).

\begin{tabular}{lllll}
\hline Yöntem & Özellik & $\begin{array}{l}\text { Doğruluk } \\
\text { oranı }(\boldsymbol{\%})\end{array}$ & $\begin{array}{l}\text { Hassaslık } \\
(\boldsymbol{\%})\end{array}$ & $\begin{array}{l}\text { Özgüllük } \\
(\boldsymbol{\%})\end{array}$ \\
\hline $\mathrm{kNN}(\mathrm{k}=1)$ & GSEM & 71.20 & 71.22 & 71.24 \\
\hline $\mathrm{kNN}(\mathrm{k}=2)$ & GSEM & 65.23 & 68.20 & 65.99 \\
\hline $\mathrm{kNN}(\mathrm{k}=5)$ & GSEM & 70.05 & 69.99 & 69.90 \\
\hline $\mathrm{kNN}(\mathrm{k}=10)$ & GSEM & 69.10 & 68.93 & 68.39 \\
\hline DVM & GSEM & 70.47 & 70.35 & 69.71 \\
\hline
\end{tabular}

Tablo 2'ye bakıldığında en iyi performans sonuçları kNN yöntemi ile ve k=1 uzaklığa göre bakıldığında \%67.13 doğruluk oranı elde edilmiştir. Tablo 3’te ise veri seti çapraz doğrulanarak sonuçlar incelendiğinde yine en iyi sonuçların $\mathrm{kNN}$ yöntemi ile ve $\mathrm{k}=1$ olarak belirlendiğinde $\% 71.20$ doğruluk oranı elde edildiği görülmektedir. Normal TM ve Anormal görüntülerini ayırt etme başarıları olan özgüllük ve hassasiyet değerleri ise sirasıyla \%71.24 ve \%71.22 olarak elde dilmiştir.

$\mathrm{Bu}$ deneysel çalışmanın ikinci aşamasında ise 16 özellikli GSEM özellik vektörüne RGB renk kanalları ortalamasının 3 özelliği de eklenerek sınıflandırma başarısı üzerinde etkisinin belirlenmesi için aynı parametreler ve performans ölçütleri sınıflandırma performansı Tablo 4 ve Tablo 5'te verilmiştir.

Tablo 4. GSEM + RKO özellikleri ile Normal TM ve Anormal TM görüntülerinin sınıflandırılması (\% $\%$-\%30)

\begin{tabular}{lcccc}
\hline \multicolumn{1}{c}{ Yöntem } & \multicolumn{1}{c}{ Özellik } & $\begin{array}{c}\text { Doğruluk } \\
\text { oranı }(\boldsymbol{\%})\end{array}$ & $\begin{array}{c}\text { Hassaslık } \\
(\boldsymbol{\%})\end{array}$ & $\begin{array}{c}\text { Özgüllük } \\
(\boldsymbol{\%})\end{array}$ \\
\hline $\mathrm{kNN}(\mathrm{k}=1)$ & GSEM + RKO & 71.32 & 71.44 & 70.48 \\
\hline $\mathrm{kNN}(\mathrm{k}=2)$ & GSEM + RKO & 66.43 & 70.28 & 67.76 \\
\hline $\mathrm{kNN}(\mathrm{k}=5)$ & GSEM + RKO & 69.58 & 69.42 & 68.83 \\
\hline $\mathrm{kNN}(\mathrm{k}=10)$ & GSEM + RKO & 68.53 & 68.65 & 67.63 \\
\hline DVM & GSEM + RKO & 72.73 & 72.62 & 72.36 \\
\hline
\end{tabular}


Tablo 5 GSEM + RKO özellikleri ile Normal TM ve Anormal TM görüntülerinin sınıflandırılması (5 katlı çapraz doğrulama)

\begin{tabular}{ccccc}
\hline Yöntem & Özellik & $\begin{array}{c}\text { Doğruluk } \\
\text { oranı (\%) }\end{array}$ & $\begin{array}{c}\text { Hassaslık } \\
(\boldsymbol{\%})\end{array}$ & $\begin{array}{c}\text { Özgüllük } \\
(\mathbf{\%})\end{array}$ \\
\hline $\mathrm{kNN}(\mathrm{k}=1)$ & GSEM + RKO & 70.88 & 70.88 & 69.80 \\
\hline $\mathrm{kNN}(\mathrm{k}=2)$ & GSEM + RKO & 65.23 & 67.77 & 65.69 \\
\hline $\mathrm{kNN}(\mathrm{k}=5)$ & GSEM + RKO & 69.73 & 69.61 & 69.41 \\
\hline $\mathrm{kNN}(\mathrm{k}=10)$ & GSEM + RKO & 69.00 & 68.85 & 68.21 \\
\hline $\mathrm{DVM}$ & GSEM + RKO & 74.13 & 74.03 & 73.77 \\
\hline
\end{tabular}

GSEM özelliklerine RKO eklendiği zaman her performans metriğinde de artış olduğu belirlenmiştir. Veri seti \%70 eğitim, \%30 test olarak ayrıldığında doğruluk oranı \%5,6 oranında DVM yöntemi ile arttı̆̆ gözlemlenmiştir. Çapraz doğrulama sonuçlarına bakıldığı zaman da \%3.66 oranında artarak \%74.13 doğruluk oranı elde edilmiştir. Anormal TM görüntüleri ayırt etme başarısı \%74.03 iken Normal TM görüntüleri ayırt etme başarısı ise \%73.77 olarak belirlenmiştir.

İkinci deneysel çalışmada ilk olarak görüntüler 227x227px olarak yeniden boyutlandırıldıktan sonra YGH algoritması ile TM görüntülerine ait özellik vektörü elde edilmiştir. Ardından kNN ve DVM yöntemi ile sınıflandırma sonuçlarına bakılmıştır. Veri seti \%70 eğitim ve \%30 test olarak ayırılmış ve aynı zamanda 5-katlı çapraz doğrulama sonuçları ile model performansı ölçülmüştür. Tablo 6 ve Tablo 7'de performans sonuçları verilmiştir.

Tablo 6. YGH özellikleri ile sınıflandırma sonuçları (\%70-\%30).

\begin{tabular}{llrcc}
\hline \multicolumn{1}{c}{ Yöntem } & Özellik & $\begin{array}{c}\text { Doğruluk } \\
\text { oranı (\%) }\end{array}$ & $\begin{array}{c}\text { Hassaslık } \\
(\boldsymbol{\%})\end{array}$ & $\begin{array}{c}\text { Özgüllük } \\
(\boldsymbol{\%})\end{array}$ \\
\hline $\mathrm{kNN}(\mathrm{k}=1)$ & YGH & 67.13 & 67.03 & 63.11 \\
\hline $\mathrm{kNN}(\mathrm{k}=2)$ & $\mathrm{YGH}$ & 59.79 & 62.91 & 60.83 \\
\hline $\mathrm{kNN}(\mathrm{k}=5)$ & $\mathrm{YGH}$ & 67.48 & 69.66 & 70.87 \\
\hline $\mathrm{kNN}(\mathrm{k}=10)$ & YGH & 63.63 & 63.63 & 62.59 \\
\hline $\mathrm{DVM}$ & YGH & 67.13 & 66.89 & 66.39 \\
\hline
\end{tabular}

Tablo 7. YGH özellikleri ile sınıflandırma sonuçları (5-katlı çapraz doğrulama).

\begin{tabular}{llrcc}
\hline \multicolumn{1}{c}{ Yöntem } & Özellik & $\begin{array}{c}\text { Doğruluk } \\
\text { oranı (\%) }\end{array}$ & $\begin{array}{c}\text { Hassaslık } \\
(\boldsymbol{\%})\end{array}$ & $\begin{array}{c}\text { Özgülllük } \\
(\boldsymbol{\%})\end{array}$ \\
\hline $\mathrm{kNN}(\mathrm{k}=1)$ & $\mathrm{YGH}$ & 64.60 & 64.44 & 64.28 \\
\hline $\mathrm{kNN}(\mathrm{k}=2)$ & $\mathrm{YGH}$ & 63.56 & 63.25 & 62.95 \\
\hline $\mathrm{kNN}(\mathrm{k}=5)$ & $\mathrm{YGH}$ & 62.30 & 63.35 & 63.86 \\
\hline $\mathrm{kNN}(\mathrm{k}=10)$ & $\mathrm{YGH}$ & 63.76 & 67.11 & 68.54 \\
\hline $\mathrm{DVM}$ & $\mathrm{YGH}$ & 68.48 & 68.33 & 68.10 \\
\hline
\end{tabular}

YGH özelliklerinin TM görüntülerini ayırt etme başarısına bakıldığı zaman veri seti eğitim ve test olarak ayırıldığında en iyi sonuçlar kNN yöntemi ile k=5 öklid komşuluk uzaklığ 1 ile elde edildiği gözlemlenmiştir. Doğruluk oranı \%67.48 iken hassaslık ve özgüllük oranları ise \%69.66 ve \%70.87 olarak ölçülmüştür. 5-katlı çapraz doğrulama sonuçlarına göre ise en iyi sonuçlar DVM yöntemi ile elde edilmiştir. Tek başına YGH özellikleri ile doğruluk hassasiyet ve özgüllük oranları sırasıyla \%68.48, \%68.33 ve 68.10 olarak gözlemlenmiştir.

$\mathrm{Bu}$ deneysel çalışmanın ikinci aşamasında RKO özelliklerinin eklenmesi ile modelin performans sonuçları incelenmiştir. Tablo 8 ve Tablo 9'da deneysel sonuçlar verilmiştir. 
Tablo 8. YGH + RKO özellikleri ile sınıflandırma sonuçları (\%70 - \%30)

\begin{tabular}{|c|c|c|c|c|}
\hline Yöntem & Özellik & $\begin{array}{l}\text { Doğruluk } \\
\text { orani (\%) }\end{array}$ & $(\%)^{\text {Hassaslık }}$ & $(\%)$ Özgüllük \\
\hline $\mathrm{kNN}(\mathrm{k}=1)$ & YGH + RKO & 66.78 & 66.62 & 66.41 \\
\hline $\mathrm{kNN}(\mathrm{k}=2)$ & YGH + RKO & 65.03 & 66.29 & 64.64 \\
\hline $\mathrm{kNN}(\mathrm{k}=5)$ & $\mathrm{YGH}+\mathrm{RKO}$ & 63.28 & 64.61 & 65.29 \\
\hline kNN (k=10) & YGH + RKO & 60.83 & 61.34 & 61.59 \\
\hline DVM & YGH + RKO & 67.48 & 67.25 & 66.74 \\
\hline
\end{tabular}

Tablo 9. YGH + RKO özellikleri ile sınıflandırma sonuçları (5-katlı çapraz doğrulama)

\begin{tabular}{|c|c|c|c|c|}
\hline Yöntem & Özellik & $\begin{array}{l}\text { Doğruluk } \\
\text { oranı }(\%)\end{array}$ & $(\%)^{\text {Hassaslık }}$ & $\begin{array}{l}\text { Özgüllük } \\
(\%)\end{array}$ \\
\hline $\mathrm{kNN}(\mathrm{k}=1)$ & YGH + RKO & 63.66 & 63.36 & 63.06 \\
\hline $\mathrm{kNN}(\mathrm{k}=2)$ & $\mathrm{YGH}+\mathrm{RKO}$ & 60.52 & 60.94 & 59.64 \\
\hline $\mathrm{kNN}(\mathrm{k}=5)$ & $\mathrm{YGH}+\mathrm{RKO}$ & 60.52 & 61.00 & 61.23 \\
\hline $\mathrm{kNN}(\mathrm{k}=10)$ & YGH + RKO & 62.51 & 63.96 & 64.65 \\
\hline DVM & $\mathrm{YGH}+\mathrm{RKO}$ & 68.27 & 68.07 & 67.69 \\
\hline
\end{tabular}

YGH özelliklerine RKO özellikleri de eklendikten sonra veri seti \%70 eğitim ve \%30 test olarak ayırıldığında RKO değeri eklendikten sonra $\mathrm{k}=1,5,10$ komşulukları için doğruluk oranı azalırken $\mathrm{k}=2$ değeri için ortalama doğruluk değeri artmıştır. 5-katlı çapraz doğrulama ile performans sonuçlarına bakıldığı zaman RKO özellikleri eklendikten sonra tüm performans metriklerinin düş̧üğü gözlemlenmiştir.

Üçüncü deneysel çalışmada ise YİÖ özellikleri ve YIOÖ özelliklerine RKO da eklenerek TM veri setini sınıflandırma başarısına etkisi incelenmiştir. YİÖ dokusal özellik çıkarma algoritmasının $3 \times 3$ boyutunda matrislerinin yarıçap1 1 olan 8 komşuluk değerine bakılmıştır. Görüntüler $227 \times 227$ piksel olarak yeniden boyutlandırıldıktan sonra gri renkli görüntülerden özellik elde edilmiştir. Model performansını test etmek için veri seti eğitim ve test verisi olarak sırasıyla $\% 70$ 'e ve $\% 30$ olarak ayırıldıktan sonra 5-katlı çapraz doğruluma sonuçlarına da bakılmıştır. Deneysel çalışma sonucunda elde edilen bulgular Tablo 10 ve Tablo 11 'de verilmiştir.

Tablo 10. YİÖ özellikleri ile Anormal TM ve Normal TM görüntülerinin sınıflandırma sonuçları (\%70-\%30)

\begin{tabular}{|c|c|c|c|c|}
\hline Yöntem & Özellik & $\begin{array}{l}\text { Doğruluk } \\
\text { oranı }(\%)\end{array}$ & $(\%)^{\text {Hassaslık }}$ & $(\%)^{\text {Özgüllük }}$ \\
\hline $\mathrm{kNN}(\mathrm{k}=1)$ & Yİ̈̈ & 70.27 & 71.21 & 71.95 \\
\hline $\mathrm{kNN}(\mathrm{k}=2)$ & YİÖ & 70.62 & 70.68 & 69.77 \\
\hline $\mathrm{kNN}(\mathrm{k}=5)$ & YİÖ & 70.62 & 73.35 & 74.95 \\
\hline $\mathrm{kNN}(\mathrm{k}=10)$ & YİÖ & 68.18 & 70.59 & 71.93 \\
\hline DVM & YİÖ & 73.07 & 73.51 & 74.00 \\
\hline
\end{tabular}

Tablo 2. YiÖ özellikleri ile Anormal TM ve Normal TM görüntülerinin sınıflandırma sonuçları (5 katlı çapraz doğrulama)

\begin{tabular}{|c|c|c|c|c|}
\hline Yöntem & Özellik & $\begin{array}{l}\text { Doğruluk } \\
\text { oranı (\%) }\end{array}$ & $(\%)$ Hassaslık & $(\%)$ Özgüllük \\
\hline $\mathrm{kNN}(\mathrm{k}=1)$ & YİÖ & 70.99 & 71.09 & 71.21 \\
\hline $\mathrm{kNN}(\mathrm{k}=2)$ & YİÖ & 70.99 & 71.09 & 71.21 \\
\hline $\mathrm{kNN}(\mathrm{k}=5)$ & YİÖ & 71.83 & 73.54 & 74.74 \\
\hline $\mathrm{kNN}(\mathrm{k}=10)$ & Yİ̈ & 68.90 & 70.94 & 72.16 \\
\hline DVM & Yİ̈̈ & 76.33 & 76.54 & 76.87 \\
\hline
\end{tabular}


Veri setinin eğitim ve test olarak \%70'e ve \%30 olarak ayrıldığında en yüksek doğruluk oranı DVM yöntemi ile \%73.07 olarak belirlenmiştir. Çapraz doğrulama ile en yüksek sonuçları yine DVM yöntemi ile elde edilmiştir. Doğruluk, hassasiyet ve özgüllük değerleri sırasıyla \%76.33, \%76.54 ve \%76.87 olarak ölçüldüğü belirlenmiştir.

Bu deneysel çalışmaya RKO özellikleri de eklenerek YİÖ ve RKO özelliklerinin sınıflandırma başarısına olan etkisi incelenmiştir. YİÖ özelliklerinin parametreleri ise olduğu gibi alınarak aynı performans metrikleri ile model performansı ölçülmüştür. Performans sonuçları Tablo 12 ve Tablo 13'de verilmiştir.

Tablo 12. YİÖ + RKO Özellikleri ile Normal TM ve Anormal TM görüntülerinin sınıflandırılması (\%70-\%30)

\begin{tabular}{|c|c|c|c|c|}
\hline \multirow{2}{*}{ Yöntem } & \multirow{2}{*}{ Özellik } & \multirow{2}{*}{$\begin{array}{l}\text { Doğruluk } \\
\text { oranı }(\%)\end{array}$} & \multirow{2}{*}{$(\%)^{\text {Hassaslık }}$} & \multirow{2}{*}{$(\%)$ Özgüllü̈k } \\
\hline & & & & \\
\hline $\mathrm{kNN}(\mathrm{k}=1)$ & YİÖ + RKO & 71.67 & 72.65 & 73.46 \\
\hline $\mathrm{kNN}(\mathrm{k}=2)$ & YİÖ + RKO & 69.93 & 69.98 & 69.05 \\
\hline $\mathrm{kNN}(\mathrm{k}=5)$ & YİÖ + RKO & 68.53 & 70.39 & 71.52 \\
\hline $\mathrm{kNN}(\mathrm{k}=10)$ & YİÖ + RKO & 68.53 & 70.39 & 71.52 \\
\hline DVM & YİÖ + RKO & 78.67 & 78.85 & 79.17 \\
\hline
\end{tabular}

Tablo 13. YİÖ + RKO Özellikleri ile Normal TM ve Anormal TM görüntülerinin sınıflandırılması (5-katlı çapraz doğrulama)

\begin{tabular}{|c|c|c|c|c|}
\hline \multirow{2}{*}{ Yöntem } & \multirow{2}{*}{ Özellik } & \multirow{2}{*}{$\begin{array}{l}\text { Doğruluk } \\
\text { oranı (\%) }\end{array}$} & \multirow{2}{*}{$(\%)^{\text {Hassaslık }}$} & \multirow{2}{*}{$\begin{array}{l}\text { Özgüllük } \\
(\%)\end{array}$} \\
\hline & & & & \\
\hline $\mathrm{kNN}(\mathrm{k}=1)$ & YİÖ + RKO & 70.99 & 70.94 & 70.86 \\
\hline $\mathrm{kNN}(\mathrm{k}=2)$ & YİÖ + RKO & 67.43 & 68.39 & 66.86 \\
\hline $\mathrm{kNN}(\mathrm{k}=5)$ & YİÖ + RKO & 67.64 & 68.85 & 69.94 \\
\hline $\mathrm{kNN}(\mathrm{k}=10)$ & Yं̈̈̈ + RKO & 67.01 & 67.98 & 68.62 \\
\hline DVM & YİÖ + RKO & 73.71 & 73.75 & 73.80 \\
\hline
\end{tabular}

YİÖ özelliklerine RKO özellikleri de eklendikten sonra veri setinin eğitim ve test olarak ayırıldığında performans metriklerinde artış olduğu belirlenmiştir. En iyi sonuçlar DVM yöntemi ile elde dilmiştir. Doğruluk oranı \%78.67 olarak gözlemlenirken hassasiyet ve özgüllük değerleri ise \%78.85 ve \%79.17 olarak gözlemlenmiştir. Bu tüm deneysel çalışmalarda elde3 edilen en yüksek doğruluk oranıdır. Veri setinin homojen olmadığı durumlarda sınıflandırma başarısının yorumlanmasında alıcı işlem karakteristik eğrisi (AİK) yol gösteri olmaktadır. AİK eğrisi istatiksel olarak karar vermeye yarayan bir eğri grafiğidir. Sadece özgüllük ve duyarlılık değerlerinin yanı sıra eğrinin altında kalan alana da bakılmaktadır. Modelin ayırt edicilik gücü ve farklı deneysel çalışmaların kıyaslanmasını sağlar [44]. Veri setinin \%70 eğitim ve \%30 test olarak ayırıldığında elde edilen AİK eğrisi Şekil 4'te verilmiştir. Diğer yandan 5-katlı çapraz doğrulama sonuçlarına bakıldığında ise RKO özellikleri eklendikten sonra doğruluk oranında bir azalma olduğu gözlemlenmiştir. En iyi sonuçlar ise yine DVM yöntemi ile elde edilmiştir. Modelin doğruluk, hassasiyet ve özgüllük değerleri sırasıly \% $73.71, \%$ \% 73.75 ve \%73.80 olarak ölçülmüştür. 


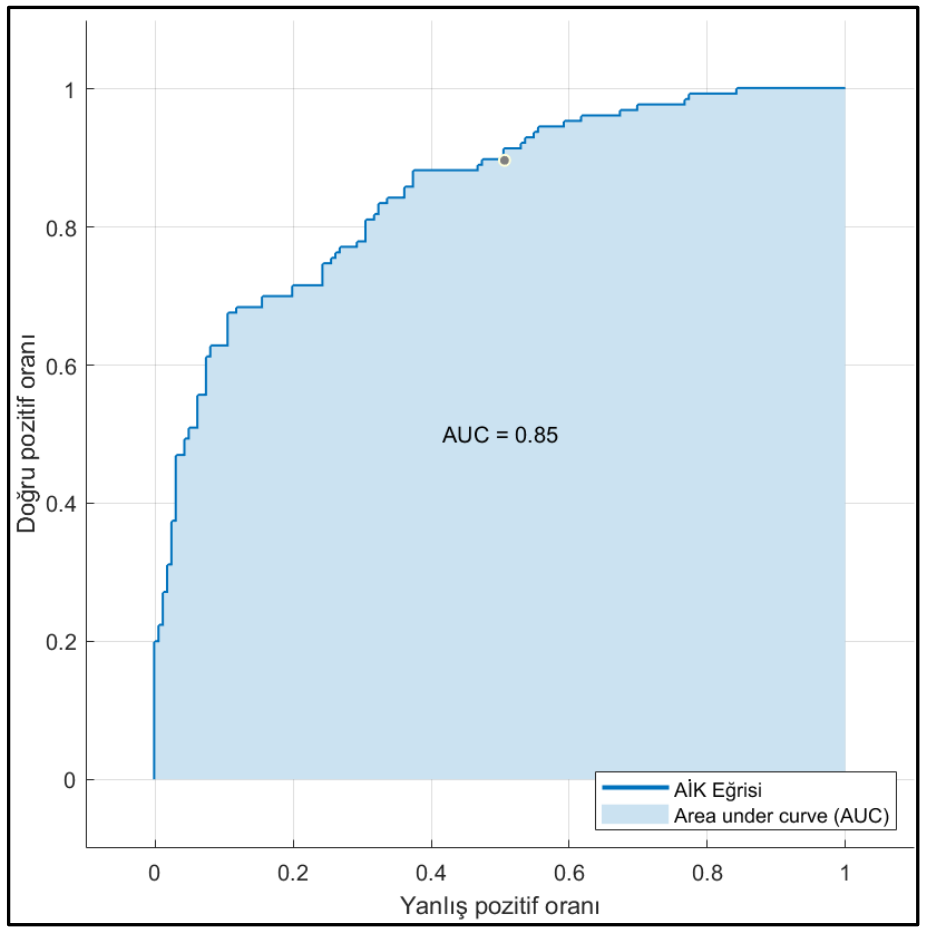

Şekil 4. YIÖ + RKO özellikleri ile DVM yöntemiyle TM görüntülerinin sınıflandırma modeline ait

Bu çalışmada GSEM, YHG, YİÖ dokusal özellik çıkarma algoritmaları ve RKO özellikleri de eklenerek makine öğrenme yöntemlerinden kNN ve DVM yöntemleri ile sınıflandırma yapılmıştır. Tablo 1 - 2 ve Tablo 7 12 sonuçlarına bakıldığında Normal TM görüntülerini ayırt etme ölçütü olan özgüllük değerlerinin hassasiyet değerlerinden daha yüksek olduğu fakat Tablo 3-6 sonuçlarına bakıldığında ise aksine daha az sayıda veriye sahip olan anormal TM görüntülerinin ayırt edici performansının daha iyi olduğu görülmektedir. Dengeli veri kümelerinde iyi performans gösteren birçok model, dengesiz muadilleri söz konusu olduğunda iyi performanslar elde edemez ve genelde çoğunluk sınıfa yönelimlidir. Bu durumu literatürü doğrular niteliktedir [45-48].

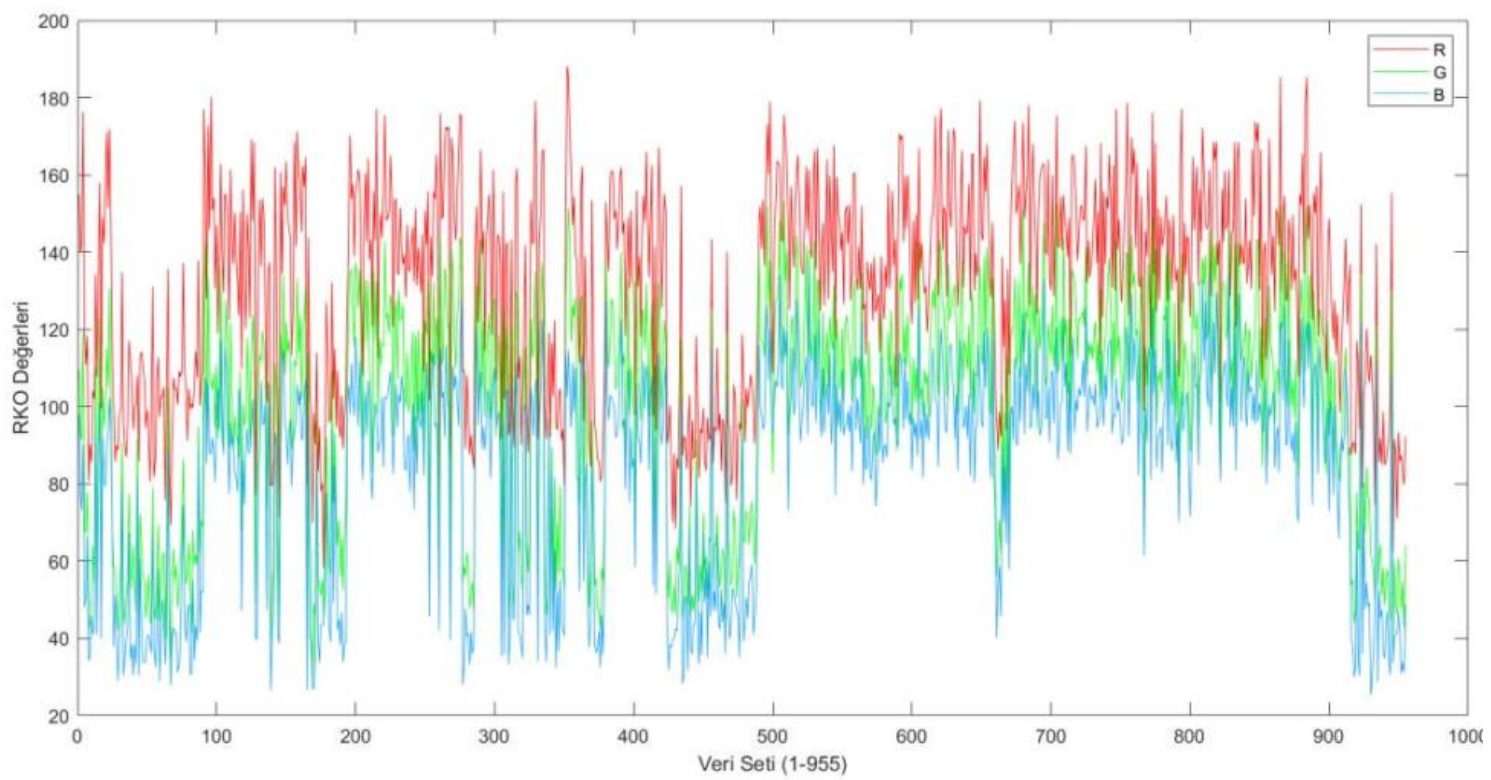

Şekil 5. Veri setinde bulunan görüntülere ait RGB değerleri 
YGH yöntemi ve RKO özelliğinin eklenmesi ile yapılan deneysel çalışmada RKO özelliği eklendikten sonra tüm performans metriklerinde düşüş olduğu görülmektedir (Tablo 8). Başaran ve arkadaşları tarafindan aynı veri seti ile sadece Akut OM TM ve Normal TM görüntüleri kullanılarak yapılan sınıflandırmaya bakıldığı zaman [13] Akut OM TM görüntülerinin çoğunlukla kırmızı renk ağırlıkta olduğu, Normal TM görüntülerinin ise gri renk ağırlıklı olmasından dolayı bu durumun RKO değerini etkilediği ifade edilmektedir. Oysa bu deneysel çalışmada anormal TM sınıf içerisinde ise Akut OM, Kronik OM, Otit Externa, Earwax gibi birçok anormal TM çeşidi bulunmaktadır. Şekil 5'e bakıldığı zaman ilk 421 görüntünün anormal TM'ye ait RGB renk dağılımlarında oldukça fazla dalgalanmanın olduğu 421'den sonra ise homojen olan tek sınıf Normal TM görüntülerde fazla dalgalanmanın olmadığı görülmektedir. Bu durum model performansını olumsuz yönde etkilemiştir.

Shie ve arkadaşları [11] YİÖ, YHG, Gabor filtre, grid color moment gibi birden fazla dokusal özellik çıkarma algoritması kullanılarak orta kulak görüntüleri sınıflandırılması çalışmasında en ayırt edici özelliğin renk özellikleri olduğu belirtilmiştir. YHG ise ayırıcılık olarak ikinci sırada yer alırken YİÖ ve Gabor özelliklerin ise OM görüntülerini ayırt etmede daha az etkiye sahip olduğu belirlenmiştir. Bu çalışmada da benzer şekilde RKO, GSEM ve YİÖ ile beraber kullanılırken sınıflandırma başarısını olumlu yönde etkilediği literatürü doğrular niteliktedir. Yine benzer şekilde Başaran ve arkadaşları tarafından AOM ve Normal TM görüntülerinin ayırt edilmesi için yapılan çalışmada [13] GSEM ve RGB renk kanallarının her birinin ayrı ayrı ortalaması alınarak özellik vektörüne eklenmesi ile sınıflandırma başarısını olumlu yönde etkilediği sonucu ile paralellik göstermektedir.

\section{Sonuc}

OM, çocuklarda ameliyatın ve antibiyotik kullanımının en yaygın sebebidir. Erken teşhis edilmesi ve tedavi sürecinin başlaması hastalığın daha kötü sekellerin önüne geçilmesi açısından son derecede önemlidir. Bu çalışmada hastalığın erken teşhis edilmesi için orta kulak otoskop görüntüleri ile bilgisayar destekli bir tanı modeli önerilmiştir.

Biyomedikal görüntülerde özelliklerin elde edilmesi için literatürde yaygın olarak kullanılan GSEM, YİÖ ve YHG algoritmaları kullanılmıştır. Tek başına bir özelik çıkarma algoritması kullanılırken en ayırt edici sonuçlar YİÖ algoritması ile \%76.33 doğruluk oranı elde edilirken, dokusal özellik çıkarma algoritmalarına RKO özelliği de eklendikten sonra yine YİÖ özellikleri ile en iyi sonuçlar \%78.67 doğruluk oranı elde edilmiştir. OM görüntülerin teşhis edilmesine yönelik dokusal özellik çıkarma algoritmasına RKO özelliğinin eklenmesi ile model performansını olumlu yönde etkilediği sonucuna varılmıştır.

Gelecekte yapılacak olan diğer çalışmalarda TM görüntülerinden birden fazla özelliği kullanılarak ve derin öğrenmenin özellik katmanları kullanılarak deneysel çalışmalar yapılması planlanmaktadır.

\section{Kaynaklar}

[1] M. Naghibolhosseini and G. R. Long, "Fractional-order modelling and simulation of human ear," Int. J. Comput. Math., vol. 95, no. 6-7, pp. 1257-1273, Jul. 2018, doi: 10.1080/00207160.2017.1404038.

[2] S. S. Balu, A. B. Deoghare, and K. M. Pandey, "Design and Modeling of Human Middle Ear for Harmonic Response Analysis," Jan. 2018, doi: 10.5281/ZENODO.1315782.

[3] W. Gao, W. Liang, and K. K. Tan, "Automated tube insertion on tympanic membrane based on vision-servo and tactile sensing," IECON Proc. (Industrial Electron. Conf., no. c, pp. 2706-2711, 2014, doi: 10.1109/IECON.2014.7048889.

[4] A. P. J. Giese, S. Ali, A. Isaiah, I. Aziz, S. Riazuddin, and Z. M. Ahmed, "Genomics of Otitis Media (OM): Molecular Genetics Approaches to Characterize Disease Pathophysiology,” Front. Genet., vol. 11, p. 313, Apr. 2020, doi: $10.3389 /$ fgene. 2020.00313 .

[5] K. Topal, "Olgularla Kulak Enfeksiyonları," vol. 10. Selen Medya Yayıncılık Tanıtım ve Organizasyon Hizmetleri, pp. 44-47, 2018.

[6] A. G. M. Schilder et al., "Otitis media," Nat. Rev. Dis. Prim., vol. 2, no. 1, p. 16063, 2016, doi: 10.1038/nrdp.2016.63.

[7] M. K. Park et al., "Differences in Antibiotic Resistance of MRSA Infections in Patients with Various Types of Otitis Media,” J. Int. Adv. Otol., vol. 14, no. 3, pp. 459-463, Dec. 2018, doi: 10.5152/iao.2018.5374.

[8] G. van Ingen et al., "Environmental determinants associated with acute otitis media in children: a longitudinal study," Pediatr. Res., vol. 87, no. 1, pp. 163-168, 2020, doi: 10.1038/s41390-019-0540-3.

[9] O. R. and A. R. Johanna M. Uitti, Miia K. Laine, Paula A. Tähtinen, "Symptoms and Otoscopic Signs in Bilateral and Unilateral Acute Otitis Media," Off. J. Am. JAcademy Pediatr., vol. 131, no. e398, pp. 398-405, 2018, doi: 10.1542/peds.2012-1188.

[10] M. Maharjan, S. Phuyal, M. Shrestha, and R. Bajracharya, "Chronic Otitis Media and Subsequent Hearing Loss in Children from the Himalayan Region Residing in Buddhist Monastic Schools of Nepal," J. Otol., 2020, doi: https://doi.org/10.1016/j.joto.2020.09.001. 
[11] C. K. Shie, H. T. Chang, F. C. Fan, C. J. Chen, T. Y. Fang, and P. C. Wang, "A hybrid feature-based segmentation and classification system for the computer aided self-diagnosis of otitis media," 2014 36th Annu. Int. Conf. IEEE Eng. Med. Biol. Soc. EMBC 2014, pp. 4655-4658, 2014, doi: 10.1109/EMBC.2014.6944662.

[12] L. Cheng, J. Liu, C. E. Roehm, and T. A. Valdez, "Enhanced video images for tympanic membrane characterization," Proc. Annu. Int. Conf. IEEE Eng. Med. Biol. Soc. EMBS, pp. 4002-4005, 2011, doi: 10.1109/IEMBS.2011.6090994.

[13] E. Başaran, A. Şengür, Z. Cömert, Ü. Budak, Y. Çelık, and S. Velappan, "Normal and Acute Tympanic Membrane Diagnosis based on Gray Level Co-Occurrence Matrix and Artificial Neural Networks," in 2019 International Artificial Intelligence and Data Processing Symposium (IDAP), 2019, pp. 1-6, doi: 10.1109/IDAP.2019.8875973.

[14] E. Başaran, Z. Cömert, A. Şengur, Ü. Budak, Y. Çelik, and M. Toğaçar, "Normal ve Kronik Hastalıklı Orta Kulak İmgelerinin Evrişimsel Sinir Ağları Yöntemiyle Tespit Edilmesi,” Türkiye Bilişim Vakfı Bilgi. Bilim. ve Mühendisliği Derg., vol. 13, no. 1, pp. 1-10, Apr. 2020, Accessed: Apr. 26, 2020. [Online]. Available: http://dergipark.org.tr/tr/pub/tbbmd/issue/53711/657649.

[15] E. Başaran, Z. Cömert, and Y. Çelik, "Convolutional neural network approach for automatic tympanic membrane detection and classification," Biomed. Signal Process. Control, vol. 56, p. 101734, Feb. 2020, doi: 10.1016/J.BSPC.2019.101734.

[16] E. Basaran, Z. Comert, A. Sengur, U. Budak, Y. Celik, and M. Togacar, "Chronic Tympanic Membrane Diagnosis based on Deep Convolutional Neural Network,” 2019, doi: 10.1109/UBMK.2019.8907070.

[17] Z. Cömert, "Otitis media için evrişimsel sinir ağlarına dayalı entegre bir tanı sistemi," Bitlis Eren Üniversitesi Fen Bilim. Derg., vol. 8, no. 4, pp. 1498-1511, Dec. 2019, doi: 10.17798/bitlisfen.600636.

[18] C. Zafer, "Fusing fine-tuned deep features for recognizing different tympanic membranes," Biocybern. Biomed. Eng., vol. 40, no. 1, pp. 40-51, 2020, doi: https://doi.org/10.1016/j.bbe.2019.11.001.

[19] E. Başaran, Z. Cömert, Y. Çelik, Ü. Budak, and A. Şengür, "Otitis media diagnosis model for tympanic membrane images processed in two-stage processing blocks."

[20] M. Toğaçar, B. Ergen, and Z. Cömert, "Detection of lung cancer on chest CT images using minimum redundancy maximum relevance feature selection method with convolutional neural networks,” Biocybern. Biomed. Eng., Nov. 2019, doi: 10.1016/J.BBE.2019.11.004.

[21] Y. Guo, Ü. Budak, and A. Şengür, "A novel retinal vessel detection approach based on multiple deep convolution neural networks," Comput. Methods Programs Biomed., vol. 167, pp. 43-48, Dec. 2018, doi: 10.1016/J.CMPB.2018.10.021.

[22] Ü. Budak, Z. Cömert, Z. N. Rashid, A. Şengür, and M. Çıbuk, "Computer-aided diagnosis system combining FCN and Bi-LSTM model for efficient breast cancer detection from histopathological images," Appl. Soft Comput., vol. 85, p. 105765, Dec. 2019, doi: 10.1016/J.ASOC.2019.105765.

[23] M. Toğaçar, B. Ergen, and Z. Cömert, "COVID-19 detection using deep learning models to exploit Social Mimic Optimization and structured chest X-ray images using fuzzy color and stacking approaches," Comput. Biol. Med., vol. 121, p. 103805, 2020, doi: https://doi.org/10.1016/j.compbiomed.2020.103805.

[24] M. Nour, Z. Cömert, and K. Polat, "A Novel Medical Diagnosis model for COVID-19 infection detection based on Deep Features and Bayesian Optimization," Appl. Soft Comput., p. 106580, 2020, doi: https://doi.org/10.1016/j.asoc.2020.106580.

[25] T. Tuncer, S. Dogan, and A. Subasi, "A new fractal pattern feature generation function based emotion recognition method using EEG," Chaos, Solitons \& Fractals, vol. 144, p. 110671, 2021, doi: https://doi.org/10.1016/j.chaos.2021.110671.

[26] M. Okaba and T. Tuncer, "An automated location detection method in multi-storey buildings using environmental sound classification based on a new center symmetric nonlinear pattern: CS-LBlock-Pat," Autom. Constr., vol. 125, p. 103645, 2021, doi: https://doi.org/10.1016/j.autcon.2021.103645.

[27] S. Salem Ghahfarrokhi and H. Khodadadi, "Human brain tumor diagnosis using the combination of the complexity measures and texture features through magnetic resonance image," Biomed. Signal Process. Control, vol. 61, p. 102025, 2020, doi: https://doi.org/10.1016/j.bspc.2020.102025.

[28] Priyanka and D. Kumar, "Feature Extraction and Selection of kidney Ultrasound Images Using GLCM and PCA," Procedia Comput. Sci., vol. 167, pp. 1722-1731, 2020, doi: https://doi.org/10.1016/j.procs.2020.03.382.

[29] A. Dongyao Jia, B. Zhengyi Li, and C. Chuanwang Zhang, "Detection of cervical cancer cells based on strong feature CNN-SVM network," Neurocomputing, vol. 411, pp. 112-127, 2020, doi: https://doi.org/10.1016/j.neucom.2020.06.006.

[30] J. Tang, Q. Su, B. Su, S. Fong, W. Cao, and X. Gong, "Parallel ensemble learning of convolutional neural networks and local binary patterns for face recognition," Comput. Methods Programs Biomed., vol. 197, p. 105622, 2020, doi: https://doi.org/10.1016/j.cmpb.2020.105622.

[31] F. Yuan, J. Shi, X. Xia, L. Zhang, and S. Li, "Encoding pairwise Hamming distances of Local Binary Patterns for visual smoke recognition," Comput. Vis. Image Underst., vol. 178, pp. 43-53, 2019, doi: https://doi.org/10.1016/j.cviu.2018.10.008.

[32] A. Güner, Ö. F. Alçin, and A. Sengür, "Automatic digital modulation classification using extreme learning machine with local binary pattern histogram features," Measurement, vol. 145, pp. 214-225, Oct. 2019, doi: 10.1016/J.MEASUREMENT.2019.05.061.

[33] N. Dalal and B. Triggs, "Histograms of oriented gradients for human detection," in 2005 IEEE Computer Society Conference on Computer Vision and Pattern Recognition (CVPR'05), 2005, vol. 1, pp. 886-893 vol. 1, doi: 10.1109/CVPR.2005.177. 
[34] M. F. Aslan, A. Durdu, K. Sabanci, and M. A. Mutluer, "CNN and HOG based comparison study for complete occlusion handling in human tracking," Measurement, vol. 158, p. 107704, 2020, doi: https://doi.org/10.1016/j.measurement.2020.107704.

[35] X. Yan, Y. Zhang, D. Zhang, and N. Hou, "Multimodal image registration using histogram of oriented gradient distance and data-driven grey wolf optimizer," Neurocomputing, Feb. 2020, doi: 10.1016/J.NEUCOM.2020.01.107.

[36] G. M. M. E Elahi, S. Kalra, L. Zinman, A. Genge, L. Korngut, and Y.-H. Yang, "Texture classification of MR images of the brain in ALS using M-CoHOG: A multi-center study," Comput. Med. Imaging Graph., vol. 79, p. 101659, 2020, doi: https://doi.org/10.1016/j.compmedimag.2019.101659.

[37] Y. Hamed, A. Ibrahim Alzahrani, A. Shafie, Z. Mustaffa, M. Che Ismail, and K. Kok Eng, "Two steps hybrid calibration algorithm of support vector regression and K-nearest neighbors,” Alexandria Eng. J., vol. 59, no. 3, pp. 1181-1190, 2020, doi: https://doi.org/10.1016/j.aej.2020.01.033.

[38] S. Zhang, "Cost-sensitive KNN classification," Neurocomputing, vol. 391, pp. 234-242, 2020, doi: https://doi.org/10.1016/j.neucom.2018.11.101.

[39] Y. Chen, B. Chen, Y. Yao, C. Tan, and J. Feng, "A spectroscopic method based on support vector machine and artificial neural network for fiber laser welding defects detection and classification," NDT E Int., vol. 108, p. 102176, 2019, doi: https://doi.org/10.1016/j.ndteint.2019.102176.

[40] R. Arian, A. Hariri, A. Mehridehnavi, A. Fassihi, and F. Ghasemi, "Protein Kinase Inhibitors' Classification Using KNearest Neighbor Algorithm," Comput. Biol. Chem., p. 107269, Apr. 2020, doi: 10.1016/J.COMPBIOLCHEM.2020.107269.

[41] M. Wadkar, F. Di Troia, and M. Stamp, "Detecting malware evolution using support vector machines," Expert Syst. Appl., vol. 143, p. 113022, 2020, doi: https://doi.org/10.1016/j.eswa.2019.113022.

[42] J. Xu, W. Tan, and T. Li, "Predicting fan blade icing by using particle swarm optimization and support vector machine algorithm," Comput. Electr. Eng., vol. 87, p. 106751, 2020, doi: https://doi.org/10.1016/j.compeleceng.2020.106751.

[43] J. Cervantes, F. Garcia-Lamont, L. Rodríguez-Mazahua, and A. Lopez, "A comprehensive survey on support vector machine classification: Applications, challenges and trends," Neurocomputing, vol. 408, pp. 189-215, 2020, doi: https://doi.org/10.1016/j.neucom.2019.10.118.

[44] L. Tomak and Y. Bek, "İşlem Karakteristik Eğrisi Analizi ve Eğri Altında Kalan Alanların Karşılaştırılması," Journal of Experimental and Clinical Medicine, vol. 27. Ondokuz Mayıs Üniversitesi, p., 2011, doi: 10.5835/jecm.v27i2.1569.

[45] L. Gao, L. Zhang, C. Liu, and S. Wu, "Handling imbalanced medical image data: A deep-learning-based one-class classification approach," Artif. Intell. Med., vol. 108, p. 101935, 2020, doi: https://doi.org/10.1016/j.artmed.2020.101935.

[46] P. Shamsolmoali, M. Zareapoor, L. Shen, A. H. Sadka, and J. Yang, "Imbalanced data learning by minority class augmentation using capsule adversarial networks," Neurocomputing, 2020, doi: https://doi.org/10.1016/j.neucom.2020.01.119.

[47] E. Duchesnay et al., "Feature selection and classification of imbalanced datasets: Application to PET images of children with autistic spectrum disorders," Neuroimage, vol. 57, no. 3, pp. 1003-1014, 2011, doi: https://doi.org/10.1016/j.neuroimage.2011.05.011.

[48] A. A. M. Karabatak, "Veri Seti - Sınıflandırma İlişkisinde Performansa Etki Eden Faktörlerin Değerlendirilmesi." Fırat Üniversitesi Mühendislik Bilimleri Dergisi, Elazığ, p. 531*540, 2020, doi: https://doi.org/10.35234/fumbd.738007. 